\title{
GIRDLING HARDWOODS TO BENEFIT CONIFERS
}

\section{W. M. ROBERTSON}

T $\mathrm{N}$ a stand of mature hardwoods with an understory of young spruce and balsam fir-the mixed type which forms the major type in this district-the Forest Service of the Department of the Interior in 1922 undertook, at its Lake Edward forest experiment station in Quebec, a study of the effect produced upon the coniferous understory, by girdling the hard. woods.

The stand selected was divided into three plots. One plot, half an acre in area, was left as a "control" plot, no girdling being done. On another plot-one acre in area-forty per cent of the hardwoods were girdled. On the third plot (also one acre in extent) all the hardwoods were girdled.

On each of these plots the regular permanent sample plot methods were used, all trees one-half inch and over in diameter being tagged, mapped, and measured at breastheight. By means of diameter-height curves and volume tables, stand tables were constructed for each plot.

In 1928 these plots were again measured and new stand tables constructed, any new conifers which had grown into the 1 -inch D. B. H.-class being tagged and measured.

An examination of the diameter increment of spruce and balsam fir during the period indicates clearly the influence of the removal of the hard. wood crown-cover. The following table shows the average increment in a number of the diameter-classes on each of the plots:-

AVERAGE DIAMETER INCREMENT 1922-1928

SPRUCE

\begin{tabular}{lccccc}
\hline Plots & & \multicolumn{5}{c}{ Diameter-classes (Inches) } \\
& 2 & 4 & 6 & 8 & 10 \\
\hline A $\quad$ (Ungirdled) & 0.10 & 0.57 & 0.31 & 0.83 & $\ldots$ \\
B $\quad$ (40\% girdled) & 0.39 & 0.87 & 0.97 & 0.72 & $\ldots$ \\
C $\quad(100 \%$ Girdled) & 0.59 & 1.09 & 1.54 & 1.04 & $\ldots$ \\
\hline BALSAM FIR & & & & & \\
A $\quad$ (Ungirdled) & 0.44 & 0.73 & 1.50 & 1.65 & 1.00 \\
B (40\% girdled) & 0.67 & 1.50 & 1.16 & 1.71 & 1.40 \\
C (100\% girdled) & 0.97 & 1.72 & 2.24 & 2.13 & 1.86 \\
\hline
\end{tabular}

While some of the diameter-classes were not well enough represented to furnish a reliable average, it can be seen at a glance that girdling and re- 
lease from the suppression of the large hardwoods has had a remarkable effect upon the rate of growth of all diameter classes. It will be noted that on the ungirdled area the rate of diameter growth of the balsam fir is much greater than that of the spruce; while both species have been benefited by the release, the superior rate of diameter growth of the balsam fir is still maintained. Expressed in percentage the increase of diameter growth ranges from 50 to 300 per cent; to this statement the 8 -inch spruce only was an exception.

Another measure of the effect of girdling is the change during the sixyear period of the numbers of trees on each of these plots. The following table shows the condition in this regard before and after girdling and at the end of the period:-

NUMBER OF TREES PER ACRE, 1922 and 1928

1 " D.B.H. and up

Plot A (Ungirdled-Control)

\begin{tabular}{lccr}
\hline & Conifers & Hardwoods & Total \\
1922 & 338 & 158 & 496 \\
1928 & 266 & 146 & 412 \\
\cline { 2 - 4 } Net Increment & -72 & -12 & -84
\end{tabular}

in 6 years

Plot B (40 Per Cent Hardwoods Girdled)

\begin{tabular}{lccr}
\hline & Conifers & Hardwoods & Total \\
1922 & & & \\
$\quad$ Before girdling & 272 & 185 & 457 \\
Number girdled & $\ldots$ & 87 & 87 \\
& 272 & 98 & 370 \\
After girdling & 322 & 79 & 401 \\
1928 & 50 & -19 & 31 \\
\cline { 2 - 4 } Net Increment & & &
\end{tabular}

in 6 years

Plot C (100 Per Cent. Hardwoods Girdled)

\begin{tabular}{lccc}
\hline 1922 & Conifers & Hardwoods & Total \\
Before girdling & 191 & 137 & 328 \\
Number girdled & $\ldots$ & 137 & 137 \\
After Girdling & 191 & $\ldots$ & 191 \\
1928 & 200 & $\ldots$ & 200
\end{tabular}


Net Increment

9

9

in 6 years

This table, of course, does not show the change in the number of trees in the various diameter-classes, but it may be stated that, in regard to the ungirdled plot, the most of the decrease in numbers of conifers shown in the table was in the very small diameter-classes. This was to be expected, as suppression of the hardwoods was very severe.

It is noticeable that on both girdled plots the number of conifers is increasing as the effect of the girdling is beginning to make itself felt. The stand of conifers in each of these cases is, of course, not sufficient to stock the area, and as time goes on it is to be expected that the younger coniferous material will fill up the gaps. It is probably not significant that the partly girdled plot has many more trees enter the one-inch class than the fully girdled plot, as this may be a result more of the former condition of the plot than directly that of the girdling. This would seem to be supported by the data in the following table of small growth taken in 1928:-

Small-Growth Table in 1928

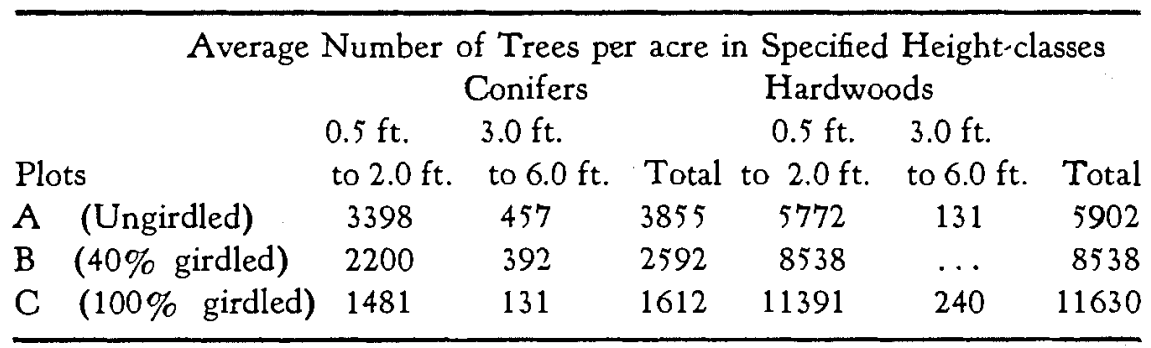

Unfortunately, no similar data is available for 1922.

The number of trees in the upper height-classes of small growth (3 feet and up) can probably be taken as a measure of the number that will enter the one-inch diameter class in the next few years. In fact, it may also be taken as a measure of the number that were nearly ready in 1922 to enter the one-inch class during the next six-year period. It was found that on Plot $A$ (ungirdled) only nine trees entered this class during the period, on Plot B ( 40 per cent girdled) 80 trees, and on Plot C ( 100 per cent girdled) only 40 trees. The small-growth table indicates that the three plots are hardly comparable in this particular. It appears that there was much more small growth on either Plot A or Plot B than on Plot C. This, therefore, must be taken into consideration when examining the results of the girdling, especially as to number of trees.

One point is very worthy of note, namely, that there is enough reproduction on any one of these plots to fill any gaps in the crown-cover; con- 
sequently, not only will the larger conifers be benefited by release, but the stand will tend to stock completely with softwoods, especially on Plot C.

Noticeable also in the small-growth table, in the case of both the girdled areas, is the large increase in the very small hardwoods and, on the other hand, the small number of larger hardwoods (three feet and over in height). This would indicate that the chances of the young hardwoods interfering with the coniferous growth are not great.

It is significant that the natural death-rate of the old hardwoods has not been altered by the release.

It is to the change in volume increment, however, that we should look for the true measure of the beneficial effect of the girdling. In the last analysis the success of this silvicultural method depends wholly upon the increased rate of production of wood of the desired species.

While the period elapsed on these plots is too short to measure correctly the benefits obtained, the results as indicated in the following tables are definitely indicative of the results to be looked for later:-

VOLUME AND INCREMENT PER ACRE 1922-1928

Plot A (Ungirdled-Control)

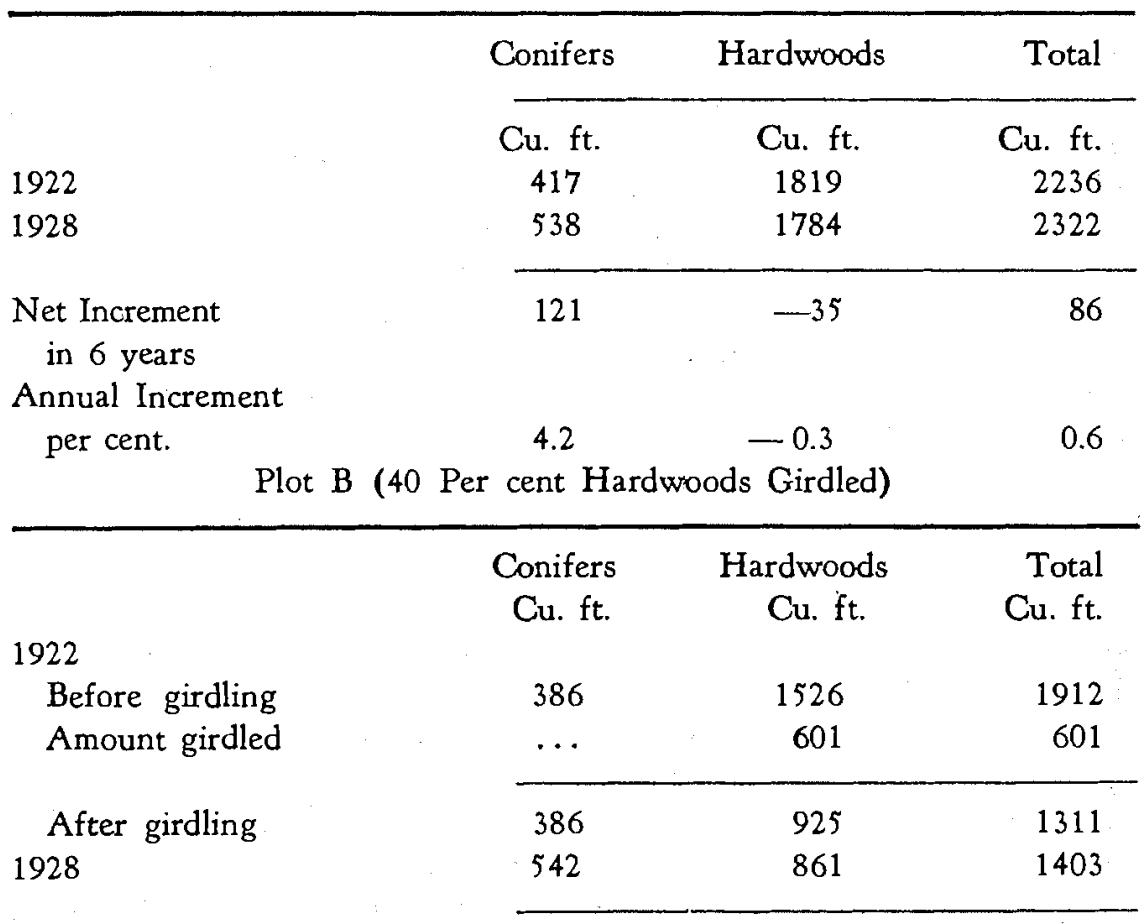


Net Increment

in 6 years

Annual Increment

per cent
156

5.6
$-64$

$-1.2$
94

1.1

Plot C (100 Per Cent Hardwoods Girdled)

\begin{tabular}{lccc}
\hline & $\begin{array}{c}\text { Conifers } \\
\text { Cu. ft. }\end{array}$ & $\begin{array}{c}\text { Hardwoods } \\
\text { Cu. ft. }\end{array}$ & $\begin{array}{c}\text { Total } \\
\text { Cu. ft. }\end{array}$ \\
Before girdling & 464 & 2620 & 3084 \\
Amount girdled & $\ldots$ & 2620 & 2620 \\
\cline { 2 - 4 } After girdling & 464 & & 464 \\
1928 & 634 & 634 \\
Net Increment & 170 & 170 \\
in 6 years & & & \\
Annual Increment & & & 5.2 \\
\hline per cent & 5.2 & & \\
\hline
\end{tabular}

It may be noticed that although these plots were selected to be as comparable as possible in number of trees and volume, they vary considerably. Most of the variance in total volume, however, is confined to the hardwoods. The volume of conifers on the plots is very similar, varying only from 386 cubic feet on Plot B to 464 cubic feet on Plot C. Moreover, the volume of hardwoods may not be a true measure of the amount of suppression. It is the size of the crowns of these old mature yellow birch and maple which determines the amount of shade produced, so that the difference in the volume of the hardwoods probably does not indicate a similar difference in shade conditions.

The effect of the release of the conifers is plainly seen in the first column of the above table. The volume increment increases from 121 cubic feet on Plot A to 156 on Plot B, and 170 on Plot C. From these figures alone it might be assumed that total girdling produced the largest increase of growth, but as the original volume of conifers was slightly different on the various plots the average annual increment per cent $(4.2,5.6$, and 5.2 re. spectively) may be a truer measure of the effect. This may be due to difference in original distribution of species and diameter classes. A better method of comparison would be to compare the same number of trees in each species distributed over the same diameter-classes; even then the comparison would be somewhat at fault. As will be noted, the effect as measured by increment percent was slightly greater on the partially girdled area than on the fully girdled one. The difference, however, is too small; and the 
evidence too meagre to justify basing any deduction in regard to the relative advantage of fully or partly girdling these plots.

Considering that the experiment is really only well started, an increased increment of nearly 50 cubic feet or one-half cord in the first six years, due solely to the girdling, is a good showing. As noted under the discussion of the number of trees, there are, and will yet be, large numbers of conifers coming into the stand. The great majority of the conifers are very young and so the increment may be expected to increase to probably one cord when the conifers become fully stocked.

While no cost data have been obtained for these plots, it can be shown from costs of girdling on other plots that they should not exceed one dollar and a half per acre.

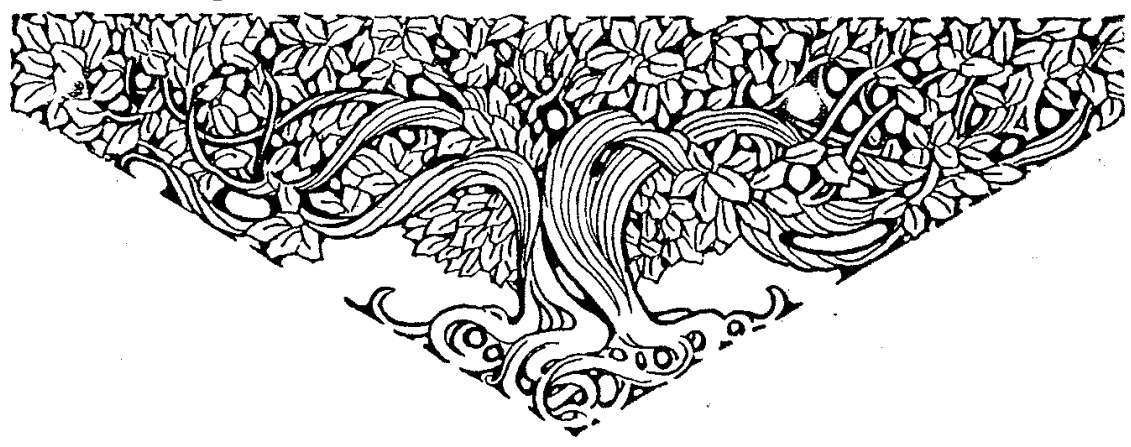

